\title{
CRIAR OS FILHOS: EXPERIÊNCIAS DE FAMÍLIAS DE TRÊS GERAÇÕES'
}

\author{
Sonia Silva Marcon² \\ Ingrid Elsen ${ }^{3}$
}

\begin{abstract}
As mudança tecnológicas ocorridas nas últimas décadas influenciaram de forma ímpar as concepções do ser humano em todas as manifestações de seu viver. A sociedade brasileira por exemplo, passou por profundas transformações demográficas, econômicas e sociais, as quais repercurtiram intensamente nas diferentes esferas da vida familiar. A urbanização associada a uma série de outras mudanças como por exemplo a inserção da mulher no mercado de trabalho, a redução no número de filhos constituem algumas das alterações que influenciaram sobremaneira a forma de criar os filhos. Assim sendo, desenvolveuse uma investigação de natureza qualitativa, com o objetivo de conhecer as experiências de famílias, ao longo de três gerações, sobre a criação dos filhos. O estudo foi realizado na cidade de Maringá, Se para as famílias, o enfrentamento de doenças, pelo menos as comuns e corriqueiras, constitui-se apenas em facetas deste criar, os profissionais de saúde precisam compreender que a doença faz parte do criar e no entanto, enquanto as famílias se preocupam coma "vida" e seu cotidiano, nós, profissionais de saúde, fazemos um recorte na realidade e passamos a agir como se esse "pedaço" da realidade representasse o todo.
\end{abstract}

Paraná, junto a famílias que tinham em comum o fato de terem tido ou terem ainda um filho, neto ou bisneto que tivesse freqüentado ou estivesse freqüentando uma creche. Na maioria das vezes as famílias foram representadas por suas mulheres. A entrevista aberta foi a estratégia básica utilizada na coleta de dados, sendo a observação e fotografias utilizadas em menor escala. O papel adotado pela pesquisadora foi do tipo conhecido pelas informantes.

Os resultados demonstraram que nas representações das famílias o criar um filho se dá inserido em um contexto e influenciado por este, e que esta experiência é única para cada família, e nas duas últimas gerações, e principalmente na última, também para cada filho. A criação é permeada pelos valores e crenças da família e também por suas concepções sobre criança, bem como sobre o papel da mulher e do homem na família. Identificou-se que na primeira geração, nas décadas de 40 e 50 as principais crenças que permearam a criação dos filhos era a de que estes deveriam ser ensinados precocemente, tanto a se comportar como a trabalhar, que deveriam ser criados junto da mãe, que havia necessidade de colocar limites na criação, que a religião era um recurso importante da criação, que os filhos tinham que ter um comportamento exemplar (obedientes, respeitadores, educados e que não roubassem) e que necessitavam estudar. Na segunda geração, nas décadas de 60 e 70 os valores e crenças predominantes eram de que a religião deveria permear a criação, que os filhos necessitavam de convivência social, de saber se comportar moral e socialmente, precisavam estudar para ter uma profissão e respeitar os mais velhos. Na terceira geração, décadas de 80 e 90, acreditase que o filho mais novo é mais esperto, que é função da família respeitar a individualidade da criança, valorizando-a como ser único no mundo, reconhecendo diferenças em sua personalidade e atendendo

\footnotetext{
1 Tese de Doutorado em Filosofia da Enfermagem, 1998. Universidade Federal de Santa Catarina.

2 Doutora em Filosofia da Enfermagem pela UFSC. Prof. Adjunto do Departamento de Enfermagem da Universidade Estadual de Maringá. Coordenadora do NEPAAF (Núcleo de Estudos, Pesquisa, Assistência e Apoio à Família)

${ }^{3}$ Orientadora do estudo, Prof. Titular da Universidade Federal de Santa Catarina.
} 
necessidades individuais; que a criança precisa ter autonomia, embora em decorrência de sua fragilidade, tenha dificuldade em ser e estar no mundo, necessitando por isto de ser cuidada o tempo todo; e, finalmente, que a criança é um ser sociável que necesśita conviver e brincar com outras crianças fora do ambiente doméstico.

As concepções de criança variaram muito, mas se mantiveram em torno de dois núcleos básicos: o comportamento e as atividades. Assim, inicialmente a criança era concebida como obediente e educada e tinha seu dia preenchido com atividades escolares e de ajuda (considerada obrigação) nos afazeres domésticos e na lavoura. Na segunda geração ela continua sendo percebida como obediente e educada e seu dia passa a ser preenchido prioritariamente com atividades escolares e brincadeiras (realizadas fora de casa), pois o trabalho passa a ter um caráter só de ajuda; atualmente a criança é representada como desobediente e sem educação para com todos e tem seu dia preenchido por atividades escolares e de lazer, passando a maior parte de seu tempo livre dentro de casa e o trabalho praticamente não faz parte da rotina das crianças desta geração.

Quanto aos valores que permeavam a criação, constata-se serem na primeira geração o estudo e a boa educação da criança (feita pela mãe e desde pequena); na segunda o estudo é inclusive exacerbado, o comportamento se volta para o social mais amplo, ou seja, aquele que a criança deveria ter em sociedade, e passa a existir uma valorização da pessoa da criança (influenciando o relacionamento entre pais e filhos). Atualmente, a valorização da criança e seu aporte psicológico determinam todo o enfoque da criação, a qual é marcada pela demonstração de afeto no relacionamento entre pais e filhos e pela preocupação com o desenvolvimento (psicológico, motor e social) da criança. As atividades que envolvem o criar, por sua vez, são determinadas pelas concepções e valores da família. Assim sendo, na primeira geração, disciplinar, educar e colocar para trabalhar constituíam a tônica; na segunda geração estas atividades continuam presentes, porém de forma menos enfática, e por outro lado, passam a fazer parte do criar o demonstrar afeto, conversar e favorecer a socialização. Finalmente, hoje em dia, estas são muito mais numerosas e guardam entre si a característica de serem realizadas quase sempre com o intuito de favorecer o desenvolvimento da criança, protegê-la ou respeitá-la em sua individualidade.

Os resultados indicam que em função de crenças e valores, apesar de toda a tecnologia disponível, a criação dos filhos hoje se mostra como uma tarefa bem mais árdua, uma vez que parece exigir maior compromisso e responsabilidade por parte dos pais.

Portanto, a compreensão do que foi e é criar um filho hoje aponta de que forma os profissionais de saúde, em especial os de enfermagem, podem e devem atuar junto às famílias. Se para as famílias, o enfrentamento de doenças, pelo menos as comuns e corriqueiras, constitui-se apenas em facetas deste criar, os profissionais de saúde precisam compreender que a doença faz parte do criar e no entanto, enquanto as famílias se preocupam com a "vida" e seu cotidiano, nós, profissionais de saúde, fazemos um recorte na realidade e passamos a agir como se esse "pedaço" da realidade representasse o todo. Em função disso, insistimos em nos preparar para atuar em situações de doença, e não contentes com isso, ainda tentamos atrair a atenção das famílias para a necessidade de se preocuparem com a doença. A falta de sincronia entre o que é vivido pela família e o preparo dos prifissionais de saúde, talvez constitua a principal justificativa para a constatação no estudo, de uma invisibilidade do profissional enfermeiro através dos tempos e, acima de tudo, nos dias atuais. Isto tem um significado concreto para a enfermagem: ela precisa rever sua prática, no sentido de dar atenção suficiente às questões que constituem a problemática do viver das famílias: saber o que é certo ou errado, como estabelecer limites, entre outros. Também é preciso reconhecer que se a família através dos tempos muda sua estrutura, sua organização, seus valores e seus papéis, a enfermagem em suas manifestações do assistir, precisa reconhecer a necessidade de pensar as famílias de forma plural (com várias possibilidades de organização), pois histórica e antropologicamente falando-se não existe um modelo de organização familiar que possa ser tido como único.

Aponta ainda que devemos nos fazer presentes, não só na doença (pois esta é esporádica e não corresponde à totalidade da vivência do criar), mas acima de tudo no cotidiano. É preciso estar presente e junto com a família descobrir meios que possam fortificá-la, mobilizá-la, impulsioná-la no alcance de seu próprio equilíbrio e bem-estar; descobrir estratégias que facilitem o desenvolvimento 
de sua tarefa de socializar e adaptar a criança a uma convivência saudável, física e mentalmente, na sociedade. Da mesma forma, estar junto com a família no aprendizado constante do desempenho de papéis, afinal as famílias hoje encontram-se em constante transformação; e por conseguinte, não são só os filhos que crescem físicamente e ao mesmo tempo precisam se desenvolver emocionalmente; os pais também precisam aprender a ser pais e a atuar como tais. Cumpre portanto, discutir e descobrir junto com a família, quanto os pais se apresentam como figuras significativas para seus filhos e, por conseguinte, como modelos a serem seguidos, surgindo assim a necessidade de um agir que possibilite, além da interação plena da família, o fornecimento de padrões adequados na formação da personalidade da criança.

Há que se estar junto com a família, tendo por objetivo fortificar e descobrir as potencialidades da mesma na condução de seu processo de viver/ser/estar saudável, para além do aspecto biológico. A abordagem deve ser no sentido de apoiá-las e fortalecê-las no enfrentamento de suas tarefas diárias, sejam ou não elas relacionadas diretamente à saúde, posto que saúde não representa mais única e exclusivamente ausência de doença.

Assim sendo, a relação entre profissionais de saúde e famílias tem que se pautar numa relação diferenciada, única. Para tanto o profissional precisa saber como o outro (família) define a situação, conhecer a cultura do outro, colocar-se no lugar do outro, precisa ouvir o outro, interagir com o outro. Precisa entender o significado que o outro dá às suas experiências, para então estar junto, crescer junto, enfim, colocar-se à disposição em ter a família como co-participante do processo de cuidar/ criar.

Isto é de fundamental importância pois, em nosso contexto, onde os serviços de assistência à saúde (que na verdade só fazem assistência à doença) não satisfazem as necessidades da população, a família tem um papel importante a desempenhar na promoção da saúde, na prevenção da doença e na recuperação da saúde. O cuidado prestado pela família em quaisquer destes níveis tem como principal característica o fato de ser permeado por relações sociais e carregadas de investimentos afetivos. E é exatamente isto que o diferencia do cuidado formal. Os investimentos afetivos têm a capacidade de estimular as forças vivas do indivíduo/família doente, promovendo com maior facilidade e rapidez a recuperação da saúde.

Conclui-se que compete ao profissional de saúde, em especial ao enfermeiro, refletir sobre o tipo de assistência a ser prestada à família no sentido de ajudá-la no desempenho desta importante tarefa que é o cuidar/zelar pela saúde de seus membros. Cada situação precisa ser entendida como uma oportunidade ímpar de colaborar adequadamente na expansão do referencial adotado pelas famílias em situações de saúde e doença. Compete pois aos profissionais de saúde, deixar que as famílias experienciem a sensação real de não estarem sós no enfrentamento de seus problemas cotidianos, como, por exemplo, o de criar os filhos.

Urge portanto repensar o ensino e a prática da enfermagem. Isto porque a formação acadêmica não tem dado conta de ampliar a visão dos profissionais no que concerne à compreensão do processo de viver, adoecer e curar, o qual ainda se encontra ancorado prioritariamente no modelo biomédico, que prioriza o atendimento individual, curativo e institucional, ou seja, não valoriza o esforço e as dificuldades da família para viver, ser/estar e se manter saudável. Na formação destes profissionais precisam ser adotadas estratégias que propiciem novas formas de abordagens, assim como o estabelecimento de novos parâmetros de assistir e cuidar, priorizando a busca da integração do cuidado formal com o informal, tendo em vista não só reconhecer, mas melhorar a qualidade do cuidado prestado pela família, tanto em situações de saúde como de doença, como meio de transformação de nossa realidade de saúde.

Os dados do estudo revelam ainda que, na interação com as famílias com o objetivo de assistilas no desempenho de suas tarefas com os filhos, o referencial a ser utilizado será o de criação conforme concebido pelas próprias famílias, o que vimos neste estudo, envolve muito mais que o apenas socializar a criança. Criar para as famílias é muito mais que educar, socializar, cuidar na doença. Criar é enxergar a criança de forma completa, com todas as suas necessidades e particularidades; é atender a essas necessidades de forma individualizada, por mais insignificantes que possam parecer. 
Finalmente, ainda na interação com a família devemos começar a utilizar claramente o termo criar, pois ele como visto ao longo do estudo representa melhor a compléxidade das tarefas desenvolvidas pelos pais (avós e outros) em relação aos filhos. Além disso, ao utilizarmos a palavra "criar" estaremos reconhecendo e acentuando o caráter de novidade imprevisível (Abbagnano, 1970) que estas tarefas possuem no dia-a-dia. Criar um filho é comparável a uma obra de arte na qual o artista vai pouco a pouco definindo os traços e a tonalidade das cores. É acima de tudo um processo inacabado, único para cada filho. Um processo que vai sendo moldado, construído pelas interações ocorridas entre os pais e entre estes e as pessoas que lhes são mais próximas, no qual se incluem os próprios filhos, os quais atuam como sujeitos de seu próprio viver. 